\title{
Experiences of non-dyslexic and dyslexic nursing and midwifery students: how best can their needs be met by Personal Academic Tutor support?
}

\author{
Anna Crouch, University of Northampton
}

\begin{abstract}
The Nursing and Midwifery Council (2008a; 2008b) not only requires employers to support nondyslexic students but also requires evidence of how disabled 'students would be supported both in clinical practice and in the academic environment to help facilitate safe and effective practice sufficient for future registration' (NMC 2004, p. 12). Limited research on personal tutor support in nursing and midwifery led to the need for a qualitative study which explored the experiences and needs of 15 non-dyslexic and 7 dyslexic nursing and midwifery students, in relation to personal academic tutor support.

Data was collected by one-to one face to face tape recorded interviews which were then transcribed using semi-structured questions. Analysis of the data by constant comparative method (Glaser \& Strauss, 1999) assisted by the computer software Nvivo8 were used to analyse data. Themes generated suggest that many of the dyslexic and non-dyslexic students in this study view their experience of their personal tutor as 'supportive' but Professional needs for both dyslexic and non-dyslexic students and their perception of how tutors could help seem to vary.
\end{abstract}

Keywords: Dyslexic students; Student support; Personal Academic Tutors

\section{Background}

According to the Nursing and Midwifery Council (NMC 2004a, p. 19) 'students should have named registrants from the same part of the register to support their learning in both academic and practice environments'. This means that, apart from the allocation of a mentor in clinical practice, a personal academic tutor is allocated to each student nurse and midwife (including those with disability) to help facilitate their academic, professional and personal development during the course of the three years nursing and midwifery education programmes.

With increasing emphasis on widening participation (Department of Health, 2000) and the requirement of employers to eliminate discrimination (Disability Rights Commission, 2002; 2004; NMC, 2008a), the recruitment of students with a disability, (particularly dyslexia) seems to be on the increase. However the prevalence of dyslexia varies both in the population and on undergraduate courses. Dale and Aitkens (2007) for instance, found that the prevalence of dyslexia ranged from 1 in 20 nursing cadets, (Illingworth, 2005) in one trust, to 3\%-10\% of nurses in others (Sanderson-Mann, 2005).

Dyslexia 'is a deficit that primarily affects literacy skills' (Griffiths, 2007, p. 277), in other words it is associated with problems related to reading and writing, as well as with speech, language processes, and memory (Morris and Turnbull, 2006; Griffiths, 2007; Crouch, 2008a; 
Crouch, 2008b). Although Ferguson (2001), Reid and Kirk, (2001) and Wiles (2001) associate skills such as problem solving, comprehension, and an ability to see the wider picture with dyslexia, the definition of dyslexia as stated above implies that dyslexic students have difficulty in writing, reading, speaking and with remembering information. This means that their academic progression might be impeded and the dyslexic student is likely to need additional support in order to complete both academic and clinical practice work successfully. Empirically, this is known to be the case for students with dyslexia and as stated by Talbot (2004) they could experience a lot of difficulties during their education and training despite the additional help given, but there is no evidence to suggest that dyslexic students are less able to complete courses than non-dyslexic students.

As stated by the NMC (2004, p. 13), 'safe and effective practice requires a sound underpinning of the theoretical knowledge, which informs practice'. Thus, fifty per cent of the three year education and training of student nurses and midwives involve attendance at the university to study the theoretical aspects of the course, and fifty per cent of the time in clinical practice (NMC, 2004a; 2004b), sometimes amidst family, personal and or social problems. The ability to register as a qualified nurse or midwife with a diploma in higher education or with a degree is dependent on the successful achievement of pass grades for all the theoretical and practical assessments (NMC, 2004a; 2004b).

Therefore the NMC (2008a; 2008b) does not only require employers to support non-dyslexic students but also require evidence of how disabled 'students would be supported both in clinical practice and in the academic environment to help facilitate safe and effective practice sufficient for future registration' (NMC, 2004b, p. 12). Although there are support systems and persons on campus for all students with or without disabilities, including staff in Student Services, the library, the Centre for Academic Practice, the Access ability unit, and the dyslexia support tutors, the role of the personal academic nursing or midwifery tutor is of great importance in the education and training of all pre-registration nursing and midwifery students.

Experience for instance, has shown that with appropriate personal academic tutor support, dyslexic students can complete their courses successfully and with good grades and good degrees (the achievement 'of a first or 2:1', TUoN, 2009a, p. 20). Statistical reports from the university also showed that $50.6 \%$ of 89 students with 'learning difficulties', including those with dyslexia who completed their degree courses achieved a good degree, compared to $54.63 \%$ of 1695 students with 'no known disability' who achieved a good degree (TUoN, 2009b: p. 2). Shellenbager (1993) and Webster (1994) also suggested that with appropriate support dyslexic students could overcome their difficulties and become even better students, but their reports were anecdotal.

Following a national survey, findings suggested that, support for students in higher education is well established (Wright, 2000). However, the data collected and published results from Wright's study were the perceptions of employers. In addition to that, Wright studied what support was available rather than how the support systems and persons operate. It was deemed important to find out students' actual experience of the available support systems or persons, but research papers related to students' experience of their personal academic tutor support in the nursing and midwifery fields appear to be very limited. There also does not appear to be any 
published research that compares the non-dyslexic and dyslexic nursing and midwifery students' experiences of their personal tutor and how best they could be supported. Moreover, there is a need to find out what students consider to be appropriate or good in terms of support provided by the personal academic tutor to help enhance the available support systems already in operation.

McGivney (1998, p.190) found that 'informal contact and rapport with tutor can provide the reassurance and encouragement they need to continue a learning programme' and that the main attribute of such a tutor are 'friendliness, availability, and interest in the student'. This means retention is likely to be enhanced when personal academic tutors are available, show interest in their students, as well as develop good rapport with their personal students during provision of support.

In a study of pharmacy students' perceptions of a personal tutorial system, the participants reported that the personal tutorial system was a means by which personal problems were listened to and that they found their personal tutors helpful (Sosabowski, et al, 2003). Although not related to nurses and or midwives, their findings seem to associate good listening skills with what the students perceived as helpful or good support which need to be taken into consideration during personal tutorials.

Recently, Hellings, et al (2008) also researched into the effectiveness of communication systems including that of the personal tutor and the student. They used six closed questions on a Likert scale and one open question. They found that of the 74 participants, $26 \%$ rated personal tutor support as very good, $19.18 \%$ as good, and $24.66 \%$ as acceptable, $21.92 \%$ as poor and $6.85 \%$ as very poor. They compared those findings with data collected in relation to module leaders support and reported that $83.8 \%$ of participants perceived module leaders' support as effective but only $69.9 \%$ of the sample said personal tutor support was effective. However, it is unclear as to what constituted very good, or very poor, or indeed what made the support effective.

It was interesting to note also that $1.37 \%$ said they did not use their personal tutor for support. Themes generated from Hellings et al's (2008) study include and suggest the need for increased access to personal tutors and more tutorials. However, their study did not specifically address issues and support for dyslexic students. The study was also specifically related to the support system within that university.

It is also imperative for the university to endeavour to enhance retention rates. Although support systems for students are well established and students are known to withdraw from their courses for different reasons, it is arguable that any form of improvement in the support systems, which includes the personal tutorial system, would help enhance retention. Although one is also aware that evaluations of support systems are carried out regularly, it is imperative that, nursing and midwifery education and training are based on research (NMC, 2004a; 2004b). Therefore, this study focussed on the students' experience of the personal academic tutor (PAT) and how support could be enhanced to help enhance their academic progress.

The aims of the study were to:

- Explore the students' experience of their personal tutor support. 
- Compare the experiences of non-dyslexic with those of dyslexic students.

- Find out how the personal tutor support could be improved for all students with particular emphasis on those with dyslexia.

Questions that were addressed were as follows:

- What is the student's experience of personal academic tutor support?

- In what ways could the personal academic tutor help to meet identified needs of the students?

- Is there any difference in the needs of dyslexic students from their personal academic tutor as compared to those of non-dyslexic student?

\section{Methodology}

The researcher sought to explore and gain a fuller understanding of the students' real world experience of their personal academic tutor within the university setting. Moreover, research literature on the topic for study was limited. Therefore a qualitative study based on the grounded theory approach was used as it aimed to generate theory from the data collected, 'that is integrated and consistent, and at the same time clear enough' to help with the formulation of questions for further studies in quantitative research (Glaser and Strauss, 1999, p.103).

Ethical approval for recruitment of participants and for carrying out the study was sought from the school of Health ethics committee and granted after which verbal and written informed consent were sought and gained from competent adults. Potential participants were also made aware of their right verbally and in writing, to withdraw from the study at any time should they so wish and without any reason which was in keeping with the University's guidance on ethics for researchers (2008). Anonymity and confidentiality was also assured and maintained by the use of numbers rather than names of participants.

\section{Participants/sample}

A convenient but purposive sample of both dyslexic and non-dyslexic students were recruited for the study to allow for comparison of data collected from the two groups. This was to help identify areas for any enhancement needed and allow for appropriate recommendation, with particular emphasis on support for dyslexic students. 22 non-dyslexic students completed the consent form and requested an interview but only 16 followed up their request and were interviewed, one of whom withdrew after the interview. 8 participants with dyslexia also requested an interview but one of them did not follow it up. Therefore samples of 15 nondyslexic as well as 7 dyslexic students were recruited for this study.

Since potential participants should be able to give the necessary information required for the study, it was important for potential participants to have had opportunity to access their personal academic tutor for support as this would have allowed some relationship to have been built. This in turn determined the inclusion and exclusion criteria below. 
Inclusion criteria for $\underline{\text { dyslexic }}$ nursing or midwifery students:

- Officially diagnosed as dyslexic

- Have accessed and used personal teacher support for at least once over the last year

\section{Exclusion criteria:}

- Not officially diagnosed as having dyslexia

- Have not used personal academic tutor for support over the last year

Inclusion criteria for non-dyslexic nursing and midwifery students:

- Have not been diagnosed as having dyslexia

- Have accessed and used personal academic tutor support at least once over the last year

\section{Exclusion criteria:}

- Have not used personal academic tutor support over the last year

\section{Recruitment}

With the permission of course leaders and teachers, I went into classrooms to give brief verbal and written information to student nurses and midwives, which allowed questions to be asked and explanation given about the study. In order to differentiate non-dyslexic and dyslexic students, participants were asked to select and put a circle around the letter $\mathbf{N}$ if s/he is nondyslexic or select and put a circle around the letter $\mathbf{D}$ if s/he has dyslexia in section 8 of the written consent form.

\section{Data collection}

Data was collected by one to one, face-to-face tape-recorded semi-structured in-depth interviews with use of open ended questions, over 20-30 minutes. This allowed participants to talk freely and in confidence, about their experiences and needs on 'the broad topic of the interview' (Robson, 2002, p. 270). This in turn led to further questioning by the researcher (Robson, 2002) for the clarification of issues raised by the participant (Stringer, 2004). The data collected was then transcribed verbatim.

The transcripts generated were numbered to help ensure anonymity and confidentiality. For example, the number D1 was used for the first dyslexic and N1 to identify transcripts generated by data collected from non-dyslexic students. The answers given by each student were also numbered to help with the easy identification of transcripts as well as with paragraphs, sentences or phrases that helped to generate themes from the data. For example, answer one by dyslexic student number one was numbered D1.1.

\section{Data analysis}

An adapted form of the constant comparative method advocated by Glaser and Strauss (1999) was used to generate themes. Words, phrases and sentences (of similar concepts) were colour coded within each and every transcript. These were constantly compared with each other to generate themes and categories, the process of which was assisted by the use of a colour-coded 
chart. The themes generated were then transferred into the NUDiST Nvivo8 software for further comparison of data, their categorisation and re-grouping until saturation occurred. This also helped to generate reports to assist with the writing up of this paper and main report.

\section{Findings: Themes generated}

Several themes were generated and grouped under three main headings (figure 1), namely

- 'The students experience of support'

- 'Problems and needs' and

- 'How the personal academic tutor could help meet needs'

Under each of the above category several themes and sub themes were generated and each will be presented and analysed separately and compared with each other, starting with the student experience of support. Brief discussion and summary then follow.

Themes generated, arranged under three main headings for both Non-dyslexic and dyslexic students

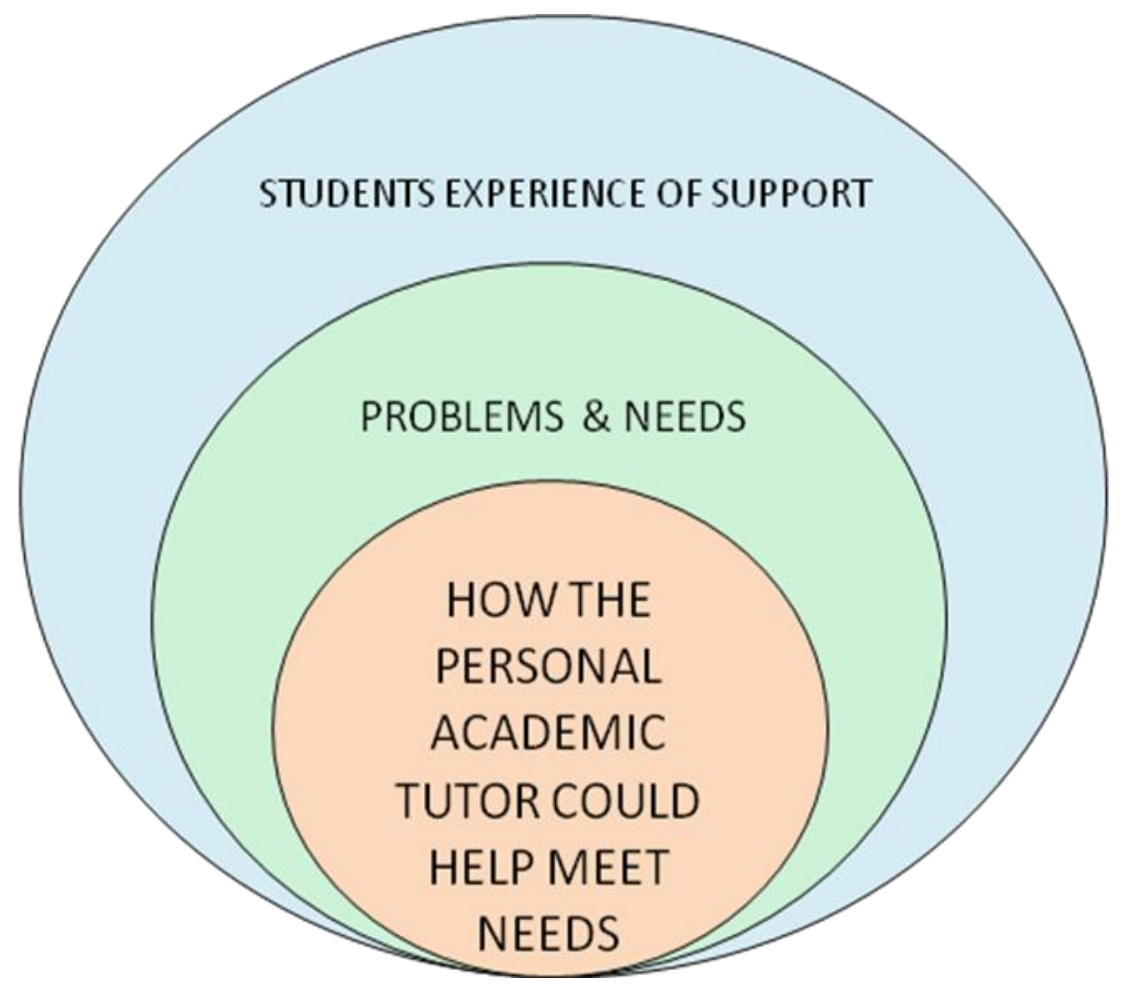

Figure 1: Categories under which themes were grouped

\section{Non-dyslexic students' experience of support}

Themes generated from data collected from non-dyslexic student nurses and midwives suggest that they found their personal academic tutors supportive (Figure 2). Sub-themes generated were 'explains things/guides', 'accessible and or available' 'helpful/ gives holistic support' 'approachable, friendly and good rapport'. 


\section{Themes generated}

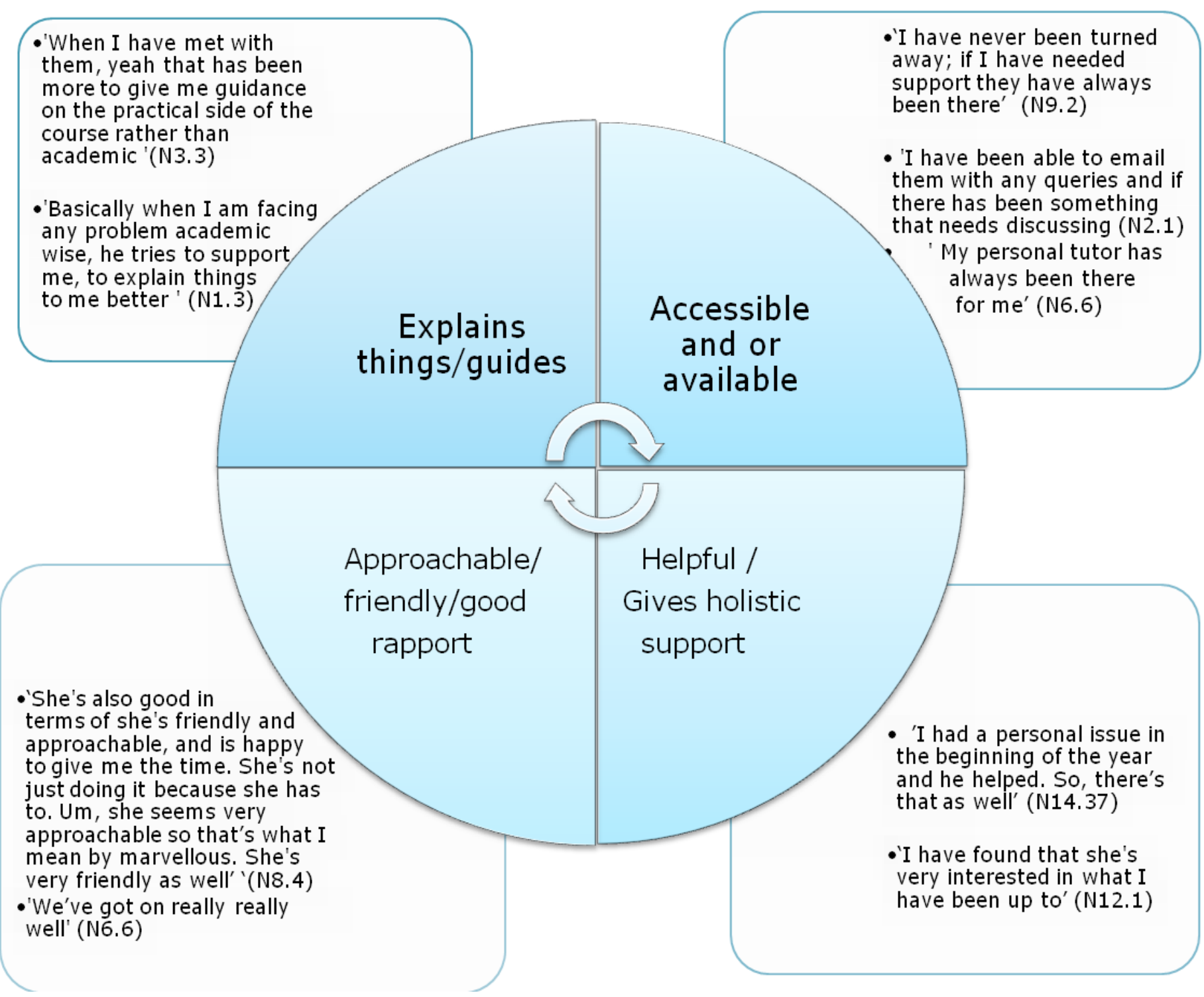

Figure 2: main theme and sub-themes (with example quotations from non-dyslexic students).

Student N1.3 (figure 2), for example, stated; 'he tries to support me, to explain things to me' which implies that s/he felt supported due to the tutors attempt to explain things to him/her. Statement N3.3 and those by other students expressed that they received guidance from their PATs (suggestive of their perception of the personal academic tutor's role as facilitators of learning). Other participants, including N6.6 expressed that they felt supported not only because they found their PATs being there for them, but also by being easily accessible through telephone, email or face to face contact when they had turned up in the tutor's office. They expressed that they did not always have to make an appointment but they had no problem in doing so when they had to, as stated by student N9.2. Moreover, they found their PATs approachable, friendly and helpful, factors which helped to develop good rapport as expressed by 
N8.4 and N6.6. As reflected in the statement by N14.37, some described the support they received either for professional or for personal issues from their PATs as helpful and comments from others suggest that their PATs showed interest by giving support in a holistic manner. In other words not only did the PATs provide academic support but also showed interest in what was going on in their personal lives as stated by student N12.1.

\section{Dyslexic students' experience of support}

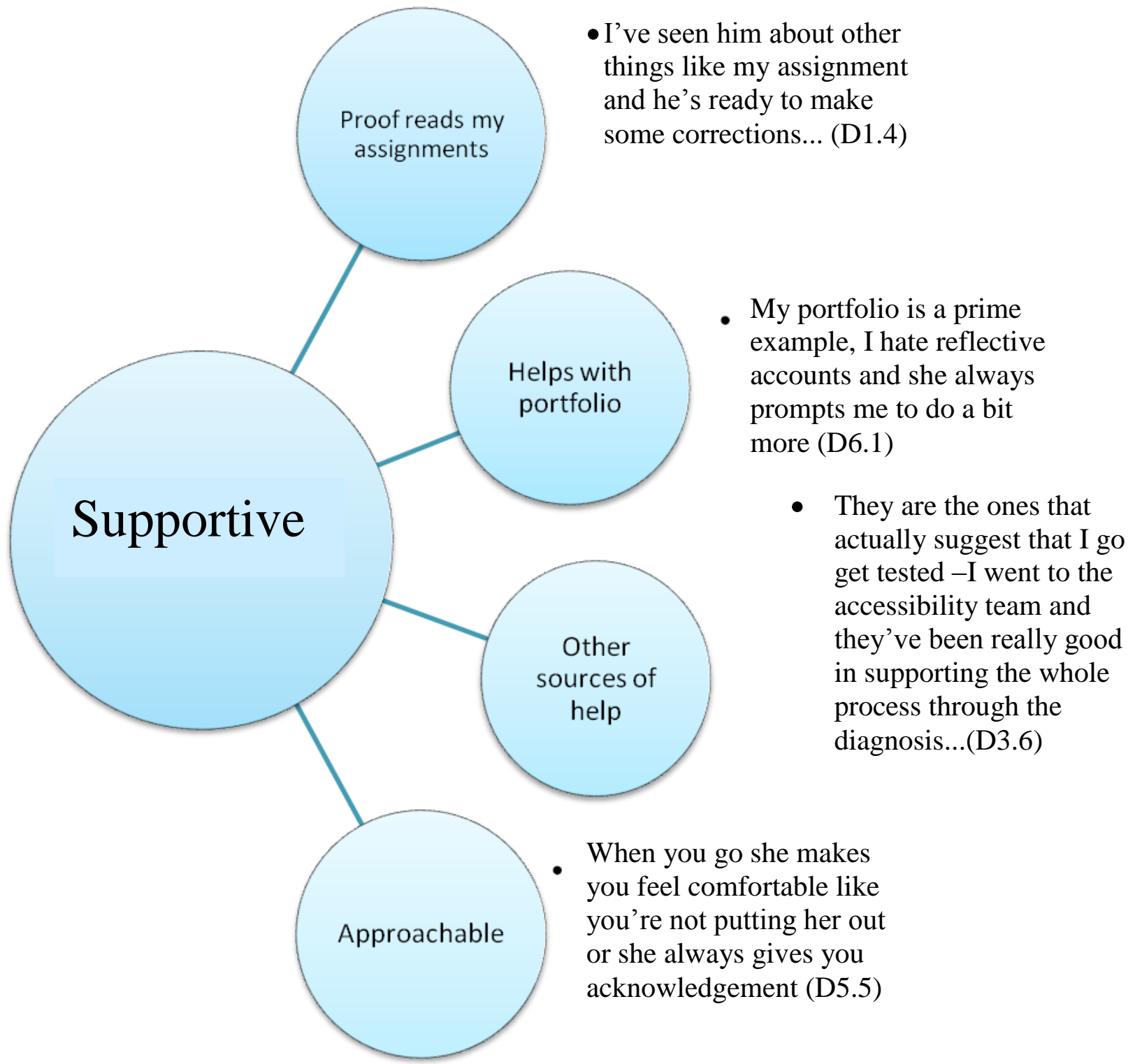

Figure 3: main theme and sub-themes (with quotations from students with dyslexia)

Experience of support (Students with dyslexia)

Themes generated from dyslexic students' data suggested that they also found their personal academic tutor supportive. Sub-themes generated from the dyslexic students, namely 'proof reads my assignment', and 'other sources of help' (figure 3) suggest that some of the reasons 
given for describing their experience as supportive seem to be different from those given by the non-dyslexic students. However like their non-dyslexic counterparts, they found their PATs approachable and received support for academic and practice issues. It also became apparent that apart from the PAT support, all the dyslexic participants tend to seek help from the access ability unit and some have tutors who deal with dyslexia allocated to them as well.

\section{Academic and professional problems and needs}

Each participant was asked to express what they thought their academic and professional needs were; the themes generated are outlined in table 1. Some expressed some of the difficulties they encounter such as 'writing difficulties', 'slow at doing things', 'problem with memory and maths' instead, but some expressed some of the difficulties they encountered as well as what they needed to overcome them (table 1).

\begin{tabular}{|c|c|}
\hline \multicolumn{2}{|c|}{ STUDENTS WITH DYSLEXIA } \\
\hline Academic problems \& needs & Academic problems \& needs \\
\hline $\begin{array}{l}\text { Difficulty with writing } \\
\text { Understanding guidelines }\end{array}$ & $\begin{array}{l}\text { Difficulty/help with writing } \\
\text { Forgetfulness } \\
\text { Slow at doing things } \\
\text { Problems with maths } \\
\text { Coping strategies }\end{array}$ \\
\hline Professional needs & Professional needs \\
\hline $\begin{array}{l}\text { Knowledge* } \\
\text { Progress to/achieve required } \\
\text { levels* }\end{array}$ & $\begin{array}{l}\text { Difficulty/help with writing } \\
\text { Forgetfulness } \\
\text { Slow at doing things } \\
\text { Problems with maths and with } \\
\text { drug calculation } \\
\text { Coping strategies }\end{array}$ \\
\hline
\end{tabular}

\section{Table 1}

It is notable from the themes generated also that both non-dyslexic and dyslexic students expressed that they had difficulty in writing assignments. However, only just under half of the sample of non-dyslexic students, but all the dyslexic students, expressed such difficulty. The latter was expected as one of the main problems associated with dyslexia is difficulty with writing (Morris \& Turnbull, 2006; Crouch 2008a \& b). Moreover, there appears to be different reasons given for this difficulty from the two groups which are reflected in the following quotations. 


\section{Non-dyslexic students}

That's it yeah, I do lovely writing about, totally about what's not being asked (N4.6)

I am not used to academic writing, which I struggle with because I APEL'D. So I missed that first foundation year (N14.2-3)

Academically I've really really struggled on this course with assignments; really really struggled I just I don't know whether I misread what they actually want. I think I read too much into what they want (N6.22)

\section{Dyslexic students}

Yes yes um when I'm formulating the essays my grammar and spelling aren't brilliant (D3.25)

..The biggest things would be spelling and grammar (D7.14)

In the above examples, it could be noted that one of the main difficulty related to writing for the non-dyslexic students appear to be misreading and possible misunderstanding of what was required, which is reflected in the other sub-theme namely 'understanding guidelines' (see table 1). This in turn has implications for practice. In contrast, the students expressed that difficulty with writing is more associated with their inability to spell, and difficulty with grammar.

There were also differences in what was expressed as professional needs for the two groups (Table 1). The non-dyslexic students expressed a need for more knowledge of certain areas of their practice and the need to achieve levels required by the NMC before registration as nurses/midwives, but only by just under a third of the total sample studied. However, the dyslexic students highlight literacy issues and other problems associated with dyslexia such as forgetfulness, slowness at doing things, and problems with mathematics, hence the need for coping strategies to overcome them (table 1).

The themes generated from dyslexic students' data for both academic and professional problems and needs were similar (table 1) which imply that any difficulties encountered by dyslexic student academically appear to impinge on their clinical practice examples of quotations of which are given below:

It takes me a bit longer to do things or understand things (D3.32)

..I've done many palpations and I'm thinking I don't get them but as I'm doing them more I am understanding how... It takes me a while to get it (D3.50)

... it's just sort of remembering formulas and things I mean if I've got them in front of me I'm fine'. (D4.5)

To do with reports and I struggle with drug calculation. (D5.35) 


\section{How best could the Personal Academic Tutor help meet student needs?}

Participants of the study were also asked to state what they thought could be done by the personal academic tutor to help meet their needs. The themes generated are outlined in table 2 .

\begin{tabular}{|c|c|}
\hline NON-DYSLEXIC STUDENTS & UDENTS WITH DYSLEXIA \\
\hline Academic: & Academic: \\
\hline $\begin{array}{l}\text { No need to bother tutor / happy with } \\
\text { ongoing support } \\
\text { More help with /I can ask for help with } \\
\text { assignment } \\
\text { One to one with tutor* } \\
\text { Give extra lecture/s to explain things } \\
\text { (APEL Students) }\end{array}$ & $\begin{array}{l}\text { Help with assignments, } \\
\text {-proof read, } \\
\text {-check assignment/plan } \\
\text {-to see if it's on right track }\end{array}$ \\
\hline Professional: (Miscellaneous) & Professional: \\
\hline $\begin{array}{l}\text { Everything is fine/ It's a mentor } \\
\text { /practice issue } \\
\text { Understand/Explain portfolio } \\
\text { More tripartite meetings (Student } \\
\text { Midwives) }\end{array}$ & It's more to do with mentor \\
\hline
\end{tabular}

\section{Table 2}

\section{Academic}

Some of the non-dyslexic students said they were happy with the support they were receiving and did not think they should bother the tutor, so did not suggest any new ways in which the personal tutor could enhance the support they were already giving as reflected in the statements below:

I think the support she's giving me is fully adequate. I'm perfectly happy with that (N10.34)

Just continuing as he is doing really, like being available and kind of helping me with the work at the same level he has been doing at the same depth because that's been very helpful to me so far, so just continuing really, haven't got many major suggestions (N11.23)

Others suggested they could perhaps ask for some more help with their assignments as reflected in the following statement:

May be I should approach her more and ask her what, you know, maybe she could explain to me a different way of doing my assignments (N6.59) 
More help needed in essay writing really (N14.42)

Other participants commented that they could 'have a one to one to with' (N1.26) the personal tutor, implying that some PATs have group tutorials but this was not explored.

The support that's given the one to one where they have gone through everything and suggest things; 'this could be used for the proficiencies' 'have you come across this, you can use this' that sort of thing (N9.18)

The APEL students suggested the need for extra lessons as stated below:

... it would have been nice to have had, I think for the APEL, those that entered by APEL, in that second year, just probably one or two extra lessons just to give us a bit of background... (N14.47)

However, some of their comments including the above appear to relate more to the course than to their PAT's support as they expressed that having started in their second year, they soon wondered what they had missed and thought perhaps they should have started with the other students. This was however not explored.

Comments from dyslexic students suggest that although they are getting some support for their assignments, more help with all assignments, such as checking through the plan, and or proof reading to ensure they are on the right track' will be appreciated as reflected in the following statement:

We have different assignments, so not just his assignment but all the other assignments... just the help and support in regards to the other assignments (D2.32)

I think kind of... going to her with what I want to do and a vague outline, that is quite useful because then she could say, 'that's on the right track or no it's not (D4.33)

\section{Professional}

With regards to meeting professional needs, some did not make any suggestions for enhancement because they felt they had no needs but students from both groups expressed that professional needs relate more to practice so they expected mentors rather than PATs to deal with them. This finding seems to have been suggested by the student nurses as reflected in the examples of statements below:

I don't think he can, I think the only person I'll be able to go to will be my clinical placement mentors because they will be working with me directly in those situations (N11.38)

I guess it's more to do with my mentor on placement rather than... my personal tutor (D4.47)

Sorry... It's more of a placement issue ... really (D7.41)

The student midwives in the study, however, commented that they would like to have more tripartite meetings which involved themselves, their mentor and the personal teacher as they have 
found this very useful, an arrangement which has been shown to improve practice assessment and enhance the students experience (Doughty et al, 2007).

\section{Discussion}

Both non-dyslexic and dyslexic students from this study expressed how their PATs gave them guidance and or explained things related to their assignments or course to them, all of which led them to describe their PATs as supportive. These seem congruent with findings from other researchers such as Tinto (1997) and Yorke (1999) who also linked contact between students and tutors with satisfactory university experience, personal development and academic achievement. This implies that the support provided by the personal academic tutors in this study is likely to facilitate academic, personal and professional development of the student and could explain why the students value highly, the contact with their PATs.

The select committees' tenth report (The Stationery Office-TSO 2008) stressed the importance of accessibility of tutors who could provide both academic and pastoral support. The students in this study linked the accessibility and availability of their PATs to very good support which is supported by findings from Drew (2001). Walsh et al (2009) also found that accessibility and availability of tutors were 'determinants of whether students used their academic tutors for support'. Thus participants in this study were probably encouraged to seek help when needed but this was not explored. This could be have been further enhanced by the fact that they found their PATs friendly and approachable and helpful (Grayson et al, 1998), factors which also contributed to developing good rapport (figure 2) and could help facilitate retention (McGivney,1998: Thomas, 2002: Prescott \& Simpson, 2004). It is arguable that the development of very good rapport with the PATs probably also encouraged the students to be able to not only seek help for academic but also for personal problems but this was not explored. 'Being seen as the sort of person that students can approach is associated with positive evaluations' (Grayson et al 1998, p. 2) which is also true of this study and stresses the importance of good studentpersonal tutor relationship in Higher education system (TSO, 2008).

The dyslexic students did however express slightly different reasons for describing their PATs as supportive, and which were more specifically related to their difficulties in writing not just assignments, but also in the completion of their portfolios and the need for help from other sources.

Apart from difficulty in writing, different problems and needs were identified by each group of participants but the reasons given for the writing difficulties are different for each group. This was expected as some of the main problems associated with dyslexia relate to poor spelling and grammar (Morris \& Turnbull, 2006; Crouch, 2008a \& b). However, the academic as well as professional problems associated with dyslexia and hence the identified need appear to be similar, which imply that the students' academic problems impact on their professional practice, which is supported by previous findings by Illingworth, (2005) Morris \& Turnbull, (2006) and by Crouch (2008a \& b). The dyslexic students had nonetheless, developed strategies for coping with their problems. 
Considering all the problems and needs identified, it was interesting to note that the main suggestion for enhancement of support for and by the dyslexic students relates to further support for assignments as some would like to know if they are on the right track. Students in Drew's study (2001, p. 315) also expressed that they wanted 'guidance to check if they were on the right lines' This was also a finding in a previous study although it related to how best to support dyslexic students in clinical practice (Crouch, 2008a \& b). The request to proof read their assignments as part of the support offered could prove challenging to some personal academic tutors as such activity is very time consuming and it is debatable as to whether it should be part of the personal academic tutors' role in relation to spelling and grammar. It would be interesting to find out personal academic tutors' perceptions on such suggestions.

The student nurses suggested that their professional needs were practice issues and expected their mentors to deal with those which imply that they perceived the role of their personal academic tutors to be more related to academic than practice issues. These findings seem to correlate with those of previous studies in which students expressed that the support of their personal tutors as practice teachers were of little importance in acquiring skills when compared to their mentors (Spouse 1996; White 1996; Newton \& Smith 1998).

Nonetheless, the student midwives requested more tripartite meetings as they found such arrangements useful, which supports findings by Doughty et al, (2007) that such support helps to enhance practice assessment as well as the students' experience so has implications for practice. Previous studies in nursing also reported that some nursing students found such form of support satisfying (White 1996; Newton \& Smith, 1998) especially where the personal teacher showed that they were genuinely interested in what the students wanted to learn, took time to talk with, as well as worked with them (Newton \& Smith, 1998). Although this has implications for practice, it is arguable that a tripartite arrangement that involves the personal academic tutor could be difficult to implement on a large scale.

Statements and suggestions made by the nursing and midwifery students imply some differences in how the personal academic tutorial systems operate within their respective departments; however, both groups of non-dyslexic and dyslexic nursing and midwifery students in this study seemed to be satisfied with the support received.

\section{Conclusion}

Analysis and discussion of the themes generated for this research are still in progress so recommendations are yet to be made. The description and discussion of findings to date do, however, appear to suggest that some of the non-dyslexic students, like their counterparts with dyslexia, identified writing difficulties as an academic problem but reasons given for such difficulties for each group appeared to be different.

The students with dyslexia reported to have more academic problems than the non-dyslexic students. Moreover, there seemed to be differences in personal academic tutor support system between the nursing and midwifery departments, but both groups reported that they found their personal academic tutors supportive and that the support given to them was appropriate to their respective needs, but some suggestions of how the support could be enhanced were made by each group. 


\section{References}

Crouch, A. (2008a) Health Sciences and Practice mini Project. Executive summary. Needs and experiences of dyslexic students + support in clinical practice. May 2008 http://www.health.heacademy.ac.uk/projects/miniprojects/projectdocs2008/acrouch_execsummar y/

Crouch, A. (2008b) Needs /experiences of dyslexic students + support in clinical practice. http://www.health.heacademy.ac.uk/projects/miniprojects/projectdocs2008/acrouch/

Dale, C. And Aiken, F. (2007) A Review of the Literature into Dyslexia in nursing Practice. Final Report. Royal College of Nursing. Practice Education Forum.

Department Of Health (2000) Looking Beyond Labels: Widening the Employment Opportunities For Disabled people in the New NHS. The Stationery Office, London.

Disability Rights Commission (2002) Disability Discrimination Act 1995 Part 4: Code of Practice for providers of Post-16 education and related services. New duties (from September (2002) in the provision of post 16 education and related services for disabled people and students' Norwich: The Stationary office. http://www.drc.gov.uk/thelaw/index.asp

Disability Rights Commission (2004b) 'Discrimination Act 1995 Code Of Practice: Trade Organisations and Qualifications Bodies' Norwich: The Stationary Office. http://www.drc.gov.uk/thelaw/index.asp

Doughty, R., Harris, T. and Mclean, M. (2007) 'Tripartite assessment of learners during practice placements in midwifery pre-registration programmes'. Education and Training. 49, (3).

Drew, S. (2001) 'Students' perceptions of what helps them to learn and develop in HE'. Teaching in Higher Education. 6 (3): 309-331.

Ferguson, J. (2001) 'A Living legend in paediatric oncology nursing: Jean Fergusson. 14 Interview by Kathy Ruccione'. Journal of Paediatric Oncology Nursing. 18 (5): 229-238.

Glaser, B. and Strauss, A .(1999) The discovery of grounded theory: Strategies for qualitative research. Aldine Transaction: New Brunswick.

Grayson, A., Clarke, D. and Miller, H. (1998) 'Help-seeking among students: Are lecturers seen as a potential source of help?' Studies in Higher Education. 23 (2): 143-155.

Griffiths, C. (2007) 'Pragmatic abilities in adults with and without dyslexia. A pilot study'. On line. www.interscience.wiley.com Dyslexia 13: 276-269 
Hellings, D., Lewis, N., Scott, C., and Sharp, E. (2008) Capturing the students' voice. Education In healthcare. Abstracts for Theme papers, symposia and Posters. Net2008 conference. $19^{\text {th }}$ annual international participative conference. Churchill College. University of Cambridge. UK.

Illingworth, K. (2005) 'The effects of dyslexia on the work of nurses and health care assistants'. Nursing Standard. 19 (38): 41-8.

McGivney, V. (1998) Guidance and retention of mature students in further education. In Crawford, M., Edwards, R., and Kydd, L. (eds) Taking issues Debates in guidance and counselling in learning. London: The Open University Routledge

Miller, W. And Crabtree, B.(1999) Depth interviewing. In Crabtree, B and Miller W. (eds) Doing qualitative research 2nd edition Thousand Oaks. Calif: Sage.

Morris, D. and Turnbull, B. (2006) 'Issues and innovations in Nursing Education. Clinical experiences of students with dyslexia'. Journal Of Advanced Nursing. 54, (2) : 238-247.

Newton, A. and Smith, N. (1998) 'Practice placement supervision: the role of the personal tutor'. Nurse Education Today. 18: 496-504.

Nursing and Midwifery Council (2004a) Standards of proficiency for pre-registration nursing education. NMC. http://www.nmc-org.uk

Nursing and Midwifery Council (2004b) Standards of proficiency for pre-registration midwifery education. NMC. http://www.nmc-org.uk

Nursing and Midwifery Council (2008a) Good health and good Character: guidance for educational institutions http://www.nmc-org.uk

Nursing \& Midwifery Council (2008b) Standards to support learning and assessment in practice http://www.nmc-uk.org/aFrameDisplay.aspx?DocumentID=4368 (accessed

24.10.08)

Prescott, A. and Simpson (2004) 'Effective student motivation commences with resolving dissatisfiers'. Journal of Further and Higher Education. 28 (3): 247-259.

Reid, G. and Kirk, J. (2001) Dyslexia in Adult education and Employment. Chichester: John Wiley and Sons.

Robson, C. (2002) Real World Research. Second Edition. Oxford: Blackwell Publishing.

Shellenbarger, K. (1993) 'Helping the dyslexic nursing student'. Nurse Educator. 18 (6): 10-13. Sosabowski, M., Bratt, A., Herson, K., Olivier, G., Sawers, R. et al (2003) 'Enhancing quality in the pharmacy degree programme: optimisation of the personal tutor system'. Pharmacy Education. 3 (2): 103-8. 
Spouse, J. (1996) 'The effective mentor: a method a model for student-centred learning in clinical practice'. NT Research. 1(2): 120-33.

Stringer, E. (2004) Focus Groups. In Bassett (2004) ( ed) Qualitative Research in healthcare. Whurr Publishers.

Talbot, C. (2004) 'Equality, Diversity and Inclusivity: Curriculum Matters'. Section 7 SEDA Special 16. Staff and Educational Development Association Ltd. http://www.seda.ac.uk

The Stationery Office (2008) Tenth Report. Department for innovation, Universities and skills (DIUS) (2010) Staying the course. The retention of students on higher education courses; http://www.official-documents.gov.uk/document/cm73/7364/7364.pdf

The University of Northampton (2008) Guidance on ethics for researchers. http://www2.northampton.ac.uk/portal/page/portal/knowledgeexchange/homepage/research/guid ance-ethics - 46k - $\underline{\text { Cached }}$ Accessed 28.10.08

The University of Northampton (2009a) Classification -Disability 08-09. Information planning Unit. University of Northampton.

The University of Northampton (2009b) Students Statistics 2008/09. Information Planning Unit. University of Northampton..

Thomas, E. (2002) 'Student retention in Higher Education: The role of institutional habitus'. Journal of Education Policy 17, (4): 423-32.

Tinto, V. (1997) 'Classrooms as communities: Exploring the educational character of student persistence'. Journal of Higher Education. 68, (6): 599-644.

Walsh, , C Larsen, C. and Parry, D. (2009) 'Academic tutors at the frontline of students succeeding in higher education’. Educational Studies. 35, (4) p: 405-424.

Webster, G. (1994) 'A student's struggle: the problems of dyslexia'. Nursing New Zealand . 2 (3): 18-19.

White, E. (1996) 'Clinical supervision \& P2000: the identification of some substantial issues'. NT Research. 1 (2): 103-111.

White, J., Williams, R. and Green B. (1999) 'Discontinuation, leaving reasons and course evaluation comments of students on the common foundation programme'. Nurse Education Today. 19: 142-150.

Wiles, J. (2001) 'There are more to nursing than the three Rs'. Nursing Times. 97 (27): 19. 
Wright, D. (2000) 'Educational support for nursing and midwifery students with dyslexia'. Nursing Standard. 14. (41): 35-41.

Yorke, M. (1999) Leaving early: Undergraduate Non-completion in Higher Education. London: Falmer Press.

\section{About the author}

Anna Crouch is Senior Lecturer in Adult Nursing in the School of Health at the University of Northampton and a University Teaching Fellow.

Email: anna.crouch@ @orthampton.ac.uk 